\title{
Intraoperative post-annuloplasty three- dimensional valve analysis does not predict recurrent ischemic mitral regurgitation
}

\author{
Frank Meijerink ${ }^{1,2^{*}}$ (D), Inez J. Wijdh-den Hamer ${ }^{1,2}$, Wobbe Bouma ${ }^{1,2}$, Alison M. Pouch ${ }^{1}$, Ahmed H. Aly ${ }^{1}$, Eric K. Lai ${ }^{1}$, \\ Thomas J. Eperjesi ${ }^{1}$, Michael A. Acker ${ }^{3}$, Paul A. Yushkevich, Judy Hung ${ }^{5}$, Massimo A. Mariani², Kamal R. Khabbaz ${ }^{6}$, \\ Thomas G. Gleason? ${ }^{7}$, Feroze Mahmood ${ }^{8}$, Joseph H. Gorman III,3 and Robert C. Gorman ${ }^{1,3}$
}

\begin{abstract}
Background: High ischemic mitral regurgitation (IMR) recurrence rates continue to plague IMR repair with undersized ring annuloplasty. We have previously shown that pre-repair three-dimensional echocardiography (3DE) analysis is highly predictive of IMR recurrence. The objective of this study was to determine the quantitative change in 3DE annular and leaflet tethering parameters immediately after repair and to determine if intraoperative postrepair 3DE parameters would be able to predict IMR recurrence 6 months after repair.

Methods: Intraoperative pre- and post-repair transesophageal real-time 3DE was performed in 35 patients undergoing undersized ring annuloplasty for IMR. An advanced modeling algorhythm was used to assess 3D annular geometry and regional leaflet tethering. IMR recurrence ( $\geq$ grade 2$)$ was assessed with transthoracic echocardiography 6 months after repair.

Results: Annuloplasty significantly reduced septolateral diameter, commissural width, annular area, and tethering volume and significantly increased all segmental tethering angles (except A2). Intraoperative post-repair annular geometry and leaflet tethering did not differ significantly between patients with recurrent $\operatorname{IMR}(n=9)$ and patients with non-recurrent IMR $(n=26)$. No intraoperative post-repair predictors of IMR recurrence could be identified.

Conclusions: Undersized ring annuloplasty changes mitral geometry acutely, exacerbates leaflet tethering, and generally fixes IMR acutely, but it does not always fix the delicate underlying chronic problem of continued left ventricular dilatation and remodeling. This may explain why pre-repair 3D valve geometry (which reflects chronic left ventricular remodeling) is highly predictive of recurrent IMR, whereas immediate post-repair 3D valve geometry (which does not completely reflect chronic left ventricular remodeling anymore) is not.
\end{abstract}

Keywords: Ischemia • mitral regurgitation • mitral valve repair • three-dimensional echocardiography

\section{Background}

Despite the general belief that undersized ring annuloplasty is the preferred surgical treatment strategy for all

\footnotetext{
* Correspondence: frankmeijerink@icloud.com

'Gorman Cardiovascular Research Group, University of Pennsylvania, Philadelphia, PA, USA

${ }^{2}$ Department of Cardiothoracic Surgery, University of Groningen, University Medical Center Groningen, Groningen, the Netherlands

Full list of author information is available at the end of the article
}

patients with ischemic mitral regurgitation (IMR), the durability of undersized ring annuloplasty is limited by the fact that recurrent IMR develops in $30 \%$ or more of patients in a few months after surgery $[1,2]$. IMR recurrence adversely affects outcome [3] and is predominantly related to continued left ventricular (LV) remodeling and worsening of tethering caused by undersized annuloplasty. The Cardiothoracic Surgical Network (CTSN)

(c) The Author(s). 2020 Open Access This article is licensed under a Creative Commons Attribution 4.0 International License, which permits use, sharing, adaptation, distribution and reproduction in any medium or format, as long as you give appropriate credit to the original author(s) and the source, provide a link to the Creative Commons licence, and indicate if changes were made. The images or other third party material in this article are included in the article's Creative Commons licence, unless indicated otherwise in a credit line to the material. If material is not included in the article's Creative Commons licence and your intended use is not permitted by statutory regulation or exceeds the permitted use, you will need to obtain permission directly from the copyright holder. To view a copy of this licence, visit http://creativecommons.org/licenses/by/4.0/ The Creative Commons Public Domain Dedication waiver (http://creativecommons.org/publicdomain/zero/1.0/) applies to the data made available in this article, unless otherwise stated in a credit line to the data. 
trial showed that the rate of recurrence after undersized annuloplasty for moderate and severe IMR might be up to $58.8 \%$ after 2 years [4]. Using three-dimensional echocardiography (3DE) and advanced valve modeling algorithms, we showed that P3 preoperative segmental leaflet tethering is a strong predictor of recurrent IMR 6 months after undersized annuloplasty [5]. In a subsequent study we showed a much higher predictive value of 3DE over two-dimensional echocardiography (2DE) for recurrent IMR [6]. In addition to preoperative 3DE predictors we are also in need of intraoperative (immediate post-repair) 3DE predictors that can guide patientspecific intraoperative surgical decision-making.

The literature on mitral valve (MV) geometry directly after annuloplasty is relatively sparse. 3DE valve analysis might give us more accurate insights into the quantitative effect of annuloplasty on mitral valve geometry. 2DE studies have shown that undersized annuloplasty may exacerbate leaflet tethering and that this may be a possible mechanism of recurrent IMR [7-9].

We hypothesized that the degree of intraoperative post-repair mitral leaflet tethering would determine the risk of IMR recurrence after undersized ring annuloplasty. We have previously published the pre-repair 3DE and 2DE results of 50 patients with IMR who underwent repair $[5,6]$, and to determine the predictive value of immediate post-repair 3DE we performed additional $3 \mathrm{DE}$ analyses in this same group of 50 patients.

\section{Methods}

This study was approved by the Institutional Review Boards of the University of Pennsylvania, the University of Pittsburgh, and the Beth Israel Deaconess Medical Center. Written informed consent was obtained from all patients.

\section{Patients and image acquisition}

Fifty patients with severe IMR underwent MV repair with an undersized annuloplasty ring. Pre- and immediate post-repair TEE was performed in all patients. Fifteen patients had intraoperative post-repair 3DE images of insufficient quality for modeling and were excluded. The remaining 35 patients were included for analysis. Table 1 shows an overview of the patient characteristics. Ring type selection was at the discretion of the surgeon.

Two-dimensional (2D) transthoracic echocardiography was performed preoperatively and six months after repair. Images were acquired through a transthoracic apical four chamber view. Severity of IMR was determined semi quantitatively with color Doppler by assessing the area of the regurgitant jet as a percentage of left atrial area in the apical four chamber view. The following grading scale was used: grade 0 , no IMR; grade 1 , less than $20 \%$; grade 2, 20 to $40 \%$; grade 3,40 to $60 \%$; and grade 4 , more than $60 \%{ }^{8}$. Recurrent IMR 6 months after repair was defined as IMR $\geq$ grade 2 .

Pre-repair real-time 3D TEE images were obtained after induction of anesthesia and prior to sternotomy. Post-repair images were obtained after MV repair and weaning off cardiopulmonary bypass. TEE images were obtained with a systolic blood pressure of at least 100 $\mathrm{mmHg}$. IMR grade was 0 (no/trace) or 1 (only mild) in all patients after repair. TEE images were also obtained for 21 patients with normal mitral valves and LV function who underwent cardiac surgery for indications other than MV disease. Images were acquired through a mid-esophageal view using a Philips IE33 (Philips Medical, Andover, MA) ultrasound system equipped with a 2- to $7-\mathrm{MHz}$ X7-2t TEE matrix transducer. During 4 cardiac cycles the images were acquired with a volumetric frame rate of $17-30 \mathrm{~Hz}$ and an imaging depth of $12-$ $16 \mathrm{~cm}$. This way a full volume real-time 3DE data set could be obtained.

\section{Image segmentation and annular and leaflet modeling} The full volume 3D data set was exported to an EchoView 5.4 (TomTec Imaging Systems, Munich, Germany) software workstation. All analyses were performed in midsystole. Techniques of annular and leaflet segmentation have been described previously $[5,6]$. The Cartesian $(\mathrm{x}, \mathrm{y}, \mathrm{z})$ coordinates of each data point of the 500-1000 data point cloud for each mitral valve were exported to Matlab (The Mathworks, Inc., Natick, MA) for quantitative analysis. We have previously shown that our 3DE modeling technique is characterized by a very small interoperator and intraoperator variability [10].

Determination or calculation of septolateral diameter, intercommissural width, transverse diameter, annular area, annular circumference, tethering area, tethering volume, tethering index, posterior- and anterior tethering angle, and segmental (mean) tethering angles were described previously $[5,6]$.

Mitral valve tethering index was calculated by dividing mitral valve tethering volume by mitral annular area. Tethering volume is strongly influenced by annular size and to correct for annular geometry we introduced the mitral valve tethering index [11].

\section{Statistical analysis}

All calculations were performed using IBM SPSS Statistics 23.0 (IBM Corporation, Chicago, IL). Continuous variables were expressed as mean \pm standard deviation. Categorical variables were expressed as percentages. Comparisons between groups were performed using Pearson $\chi^{2}$ test or Fisher exact test (two-sided) as appropriate for categorical variables and the independent samples t-test or Mann-Whitney $U$ test (two-sided) as appropriate for continuous variables. Within-group 
Table 1 Preoperative and intraoperative patient characteristics

\begin{tabular}{|c|c|c|c|}
\hline \multirow[t]{2}{*}{ Variable $^{a}$} & Normal & Non-recurrent & Recurrent \\
\hline & $(n=21)$ & $\operatorname{IMR}(n=26)$ & $\operatorname{IMR}(n=9)$ \\
\hline Age, years & $66.1 \pm 14.4$ & $67.5 \pm 9.7$ & $65.9 \pm 6.0$ \\
\hline Female & $8(38)$ & $8(31)$ & $3(33)$ \\
\hline Body mass index, $\mathrm{kg} / \mathrm{m}^{2}$ & $32.2 \pm 8.0$ & $28.4 \pm 4.3$ & $28.2 \pm 4.2$ \\
\hline \multicolumn{4}{|l|}{ Medical history } \\
\hline Hypertension & $11(52)$ & $19(73)$ & $7(78)$ \\
\hline Diabetes & $6(29)$ & $12(46)$ & $4(44)$ \\
\hline Renal insufficiency & $3(14)$ & $6(23)$ & $1(11)$ \\
\hline Atrial fibrillation & $2(10)$ & $11(42)$ & $3(33)$ \\
\hline Stroke & $2(10)$ & $2(8)$ & $1(11)$ \\
\hline Previous PCl & $3(14)$ & $7(27)$ & $4(44)$ \\
\hline Previous CABG & $2(10)$ & $3(12)$ & $4(44)$ \\
\hline NYHA class, 1-4 scale & $2.4 \pm 0.8$ & $2.3 \pm 1.0$ & $2.8 \pm 0.4$ \\
\hline IMR grade, 0-4 scale & $0.3 \pm 0.5$ & $3.0 \pm 0.7^{c}$ & $3.0 \pm 0.8^{\mathrm{d}}$ \\
\hline Inferior wall motion abnormality & $0(0)$ & $23(88)$ & $9(100)$ \\
\hline \multicolumn{4}{|l|}{ Left ventricular } \\
\hline End-diastolic diameter, $\mathrm{cm}$ & $4.7 \pm 0.8$ & $5.7 \pm 0.9^{c}$ & $6.1 \pm 0.9^{d}$ \\
\hline End-systolic diameter, cm & $3.2 \pm 0.8$ & $4.6 \pm 1.0^{c}$ & $5.1 \pm 1.4^{d}$ \\
\hline Ejection fraction, \% & $65.2 \pm 10.1$ & $36.0 \pm 15.7^{c}$ & $31.9 \pm 11.6^{\circ}$ \\
\hline \multicolumn{4}{|l|}{ Annuloplasty ring } \\
\hline Profile 3D ring ${ }^{e}$ & - & $12(46)$ & $8(89)$ \\
\hline CE Physio II ring ${ }^{f}$ & - & $7(27)$ & $1(11)$ \\
\hline CG Future band ${ }^{e}$ & - & $6(23)$ & $0(0)$ \\
\hline St. Jude tailor flexible ring ${ }^{g}$ & - & $1(4)$ & $0(0)$ \\
\hline Ring size, mm & - & $28.9 \pm 1.7$ & $28.7 \pm 1.4$ \\
\hline \multicolumn{4}{|l|}{ Concomitant procedures } \\
\hline CABG & $6(29)$ & $20(77)^{c}$ & $6(67)$ \\
\hline Aortic valve replacement & $14(67)$ & $2(8)^{c}$ & $0(0)^{d}$ \\
\hline Tricuspid valve repair & $0(0)$ & $1(4)$ & $1(11)$ \\
\hline Atrial maze & $0(0)$ & $5(19)$ & $0(0)$ \\
\hline Atrial septal defect closure & $1(5)$ & $0(0)$ & $0(0)$ \\
\hline
\end{tabular}

$3 D$ three-dimensional, CABG coronary artery bypass grafting, IMR ischemic mitral regurgitation, NYHA New York Heart Association, $P C I$ percutaneous coronary intervention

${ }^{\mathrm{a}}$ Data are presented as mean \pm standard deviation or number (\%)

${ }^{\mathrm{b}} P<0.05$ recurrent vs non-recurrent

${ }^{c} P<0.05$ non-recurrent vs normal

${ }^{\mathrm{d}} P<0.05$ recurrent vs normal

eMedtronic, Minneapolis, MN

${ }^{f}$ Carpentier-Edwards, Irvine, CA

${ }^{9}$ St. Jude Medical, St. Paul, MN

comparisons were performed using the paired samples ttest for continuous variables. Statistical significance was established at $P<0.05$.

\section{Results}

Patient characteristics

A total of 9 patients (26\%) experienced recurrent IMR 6 months after undersized annuloplasty. Based on these findings patients were divided in recurrent and non-recurrent IMR groups. Preoperative and intraoperative patient characteristics are presented in Table 1. As a reference data from 21 patients with normal mitral valves and normal LV function were included in Table 1 . None of the baseline variables were significantly different between the recurrent and non-recurrent groups. 
Table 2 Pre- and postoperative three-dimensional echocardiographic annular and leaflet tethering variables

\begin{tabular}{|c|c|c|c|c|c|c|c|}
\hline \multirow[b]{2}{*}{ Variable $^{a}$} & \multirow[b]{2}{*}{$\begin{array}{l}\text { Normal } \\
(n=21)\end{array}$} & \multicolumn{3}{|l|}{ Preoperative } & \multicolumn{3}{|l|}{ Postoperative } \\
\hline & & $\begin{array}{l}\text { Non-recurrent IMR } \\
(n=26)\end{array}$ & $\begin{array}{l}\text { Recurrent IMR } \\
(n=9)\end{array}$ & $\begin{array}{l}\text { Total } \\
(n=35)\end{array}$ & $\begin{array}{l}\text { Non-recurrent IMR } \\
(n=26)\end{array}$ & $\begin{array}{l}\text { Recurrent IMR } \\
(n=9)\end{array}$ & $\begin{array}{l}\text { Total } \\
(n=35)\end{array}$ \\
\hline Septolateral diameter, mm & $28.7 \pm 5.1$ & $31.5 \pm 4.0$ & $31.2 \pm 5.6$ & $31.4 \pm 4.4^{d}$ & $22.7 \pm 4.2$ & $21.2 \pm 2.5$ & $22.3 \pm 3.9^{c, e}$ \\
\hline Commissural width, mm & $31.4 \pm 3.2$ & $32.4 \pm 5.5$ & $31.3 \pm 7.4$ & $32.1 \pm 6.0$ & $29.3 \pm 3.3$ & $28.2 \pm 2.4$ & $29.0 \pm 3.1^{c, e}$ \\
\hline Mitral annular area, $\mathrm{mm}^{2}$ & $786 \pm 155$ & $949 \pm 232$ & $923 \pm 300$ & $942 \pm 247^{d}$ & $582 \pm 158$ & $536 \pm 71$ & $571 \pm 141^{c, e}$ \\
\hline $\begin{array}{l}\text { Mitral valve tethering } \\
\text { volume, } \mathrm{mm}^{3}\end{array}$ & $1771 \pm 689$ & $2748 \pm 1631$ & $3589 \pm 1782$ & $2964 \pm 1686^{d}$ & $1879 \pm 1211$ & $1602 \pm 537$ & $1808 \pm 1078^{c}$ \\
\hline Mitral valve tethering index & $2.25 \pm 0.70$ & $2.80 \pm 1.23$ & $3.68 \pm 1.13$ & $3.03 \pm 1.25^{d}$ & $3.03 \pm 1.26$ & $2.98 \pm 0.84$ & $3.01 \pm 1.15^{\mathrm{e}}$ \\
\hline \multicolumn{8}{|l|}{ Segmental tethering angle, $^{\circ}$} \\
\hline $\mathrm{A} 1$ & $18.4 \pm 9.2$ & $19.4 \pm 8.6$ & $24.2 \pm 7.8$ & $20.6 \pm 8.6$ & $27.2 \pm 11.4$ & $26.6 \pm 12.1$ & $27.1 \pm 11.4^{c, e}$ \\
\hline $\mathrm{A} 2$ & $15.0 \pm 8.2$ & $26.5 \pm 11.2$ & $32.5 \pm 12.3$ & $28.1 \pm 11.6^{d}$ & $26.9 \pm 12.5$ & $31.9 \pm 12.3$ & $28.2 \pm 12.4^{\mathrm{e}}$ \\
\hline A3 & $9.5 \pm 6.4$ & $13.8 \pm 12.1$ & $22.8 \pm 10.4$ & $16.2 \pm 12.2^{d}$ & $24.1 \pm 10.0$ & $29.2 \pm 6.1$ & $25.4 \pm 9.4^{c, e}$ \\
\hline P1 & $16.5 \pm 8.5$ & $23.3 \pm 12.9$ & $28.5 \pm 6.2$ & $24.6 \pm 11.7^{d}$ & $43.2 \pm 13.6$ & $46.5 \pm 9.4$ & $44.1 \pm 12.6^{c, e}$ \\
\hline P2 & $17.9 \pm 12.0$ & $27.4 \pm 17.4$ & $42.5 \pm 9.1^{b}$ & $31.3 \pm 16.9^{d}$ & $53.8 \pm 11.6$ & $51.7 \pm 12.9$ & $53.3 \pm 11.8^{c, e}$ \\
\hline P3 & $14.0 \pm 7.6$ & $18.4 \pm 14.1$ & $33.8 \pm 4.2^{b}$ & $22.3 \pm 14.0^{d}$ & $43.7 \pm 11.8$ & $42.0 \pm 11.6$ & $43.3 \pm 11.6^{\mathrm{c}, \mathrm{e}}$ \\
\hline
\end{tabular}

IMR ischemic mitral regurgitation

${ }^{a}$ Data are presented as mean \pm standard deviation

${ }^{\mathrm{b}} P<0.05$ recurrent vs non-recurrent

${ }^{c} P<0.05$ post-repair vs pre-repair

${ }^{\mathrm{d}} P<0.05$ pre-repair vs normal

${ }^{\mathrm{e}} P<0.05$ post-repair vs normal

\section{Annular and leaflet geometry}

In Table 2 an overview is given of all annular and leaflet tethering measurements, before and after ring annuloplasty. All annular parameters were significantly reduced after annuloplasty $(P<0.05$ for all variables). MV tethering volume was significantly reduced $(P<0.05)$, tethering index did not change significantly $(P=0.96)$. All segmental tethering angles significantly increased after annuloplasty, except for the A2 tethering angle. The posterior tethering angles (P1-P3) changed most $\left(>20^{\circ}\right)$. Figure 1 shows plots of the regional mitral valve tethering patterns against the distance traveled between the anterior and posterior commissure.

A comparison between the non-recurrent and recurrent IMR subgroups was made in Table 2. For the pre-operative annular measurements there was no significant difference between the recurrent and non-recurrent groups. For the tethering variables, P2 and P3 tethering angles were significantly different $(P<0.05)$. All postoperative annular and tethering variables were not significantly different between recurrent and non-recurrent groups. Figure 2 shows representative 3D reconstructions of normal and pre- and postrepair mitral valves that will or will not develop recurrent IMR 6 months after repair.

\section{Discussion}

Undersized annuloplasty is generally still considered the preferred surgical treatment strategy for IMR $[1-3,12$, 13]. Despite successful initial elimination of IMR, its durability is limited by high recurrence rates. In this study a recurrence rate of $26 \%$ was observed at 6 months. Earlier studies reported recurrence in approximately one third of the patients within 12 months after the procedure $[1,2,13]$. Recurrence adversely affects outcome [3] and therefore preoperative identification of patients who are at risk of IMR recurrence after undersized annuloplasty repair is of paramount importance to optimize the results of mitral valve surgery for IMR. Our previous work showed that 3DE valve analysis is highly predictive of recurrent IMR, with P3 tethering angle as a very strong independent predictor for recurrent IMR [5]. We also showed that a 3DE-based predictive model was stronger than a $2 \mathrm{DE}$ based predictive model in the same population [6]. In addition to the need to be able to preoperatively identify patients who are at risk of IMR recurrence after repair, there is a clear need for powerful intraoperative (immediate post-repair) 3DE (geometric) predictors that can identify patients at risk of IMR recurrence and guide patient-specific intraoperative surgical decision-making. The current study was designed to provide insights into this relatively unknown area.

This post-repair study clearly shows the immediate effect of undersized annuloplasty on 3D annular and leaflet geometry. Although MV tethering volume was significantly reduced after repair, which can be explained by the fact that the mitral annular area is extensively reduced by annuloplasty, leaflet tethering increases significantly in nearly all segments. An important finding in this study is the very high and significant increase in posterior leaflet tethering. This is in line with the results 

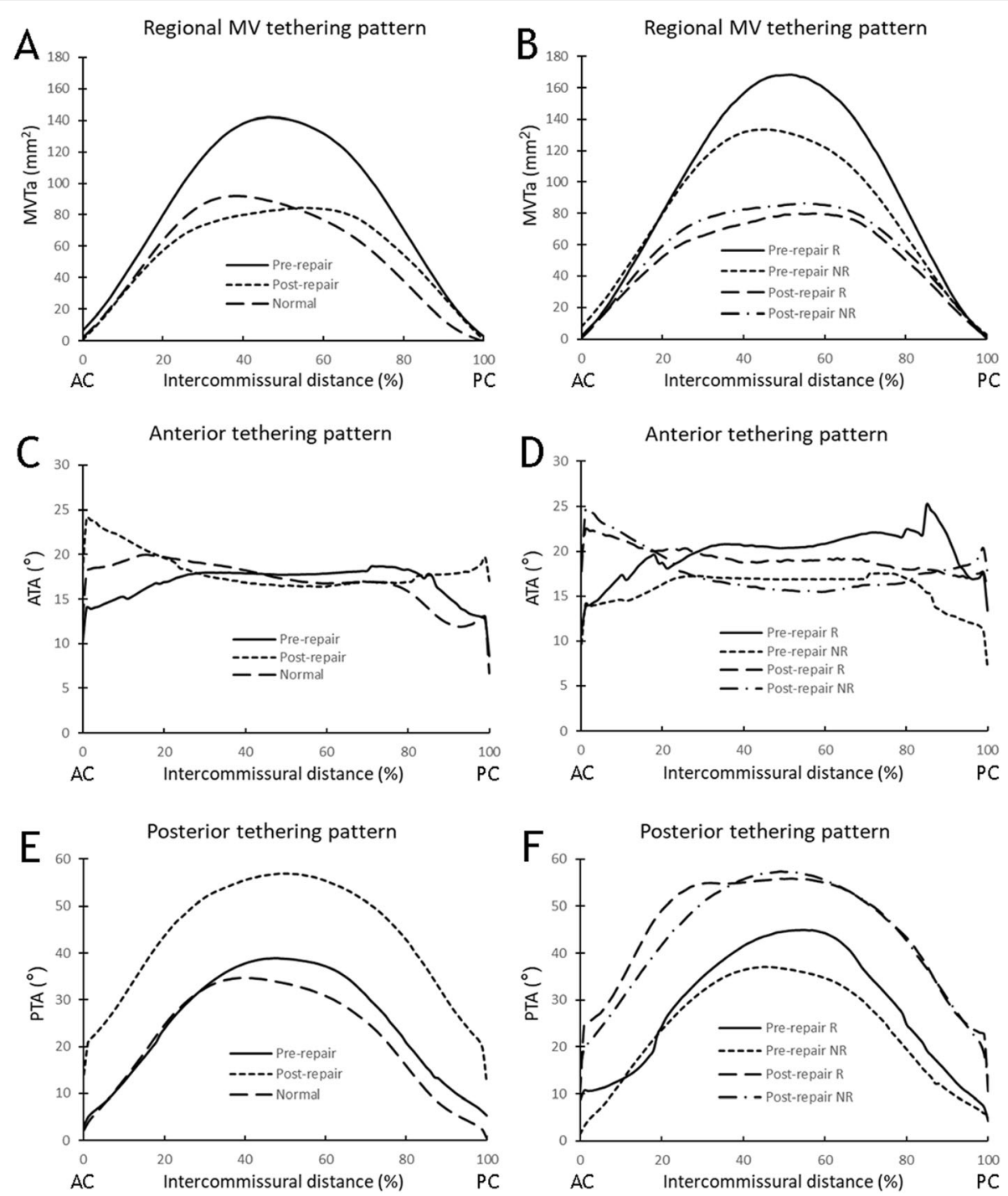

Fig. 1 Pre- and post-repair regional mitral valve tethering patterns plotted against the distance travelled between the anterior commissure (AC) and posterior commissure (PC), (a, b) Regional mitral valve tethering area (MVTa) distribution pre- and post-repair. (c, d) Regional anterior tethering angle (ATA) distribution pre- and post-repair. (e, $\mathbf{f})$ Regional posterior tethering angle (PTA) distribution pre- and post-repair. MVTa, ATA and PTA are plotted as a function of intercommissural distance, expressed as a percentage of the distance traveled from the AC. The positions of the $A C$ and $P C$ are 0 and $100 \%$, respectively. $N R=$ non-recurrent; $R=$ recurrent

of previous $2 \mathrm{DE}$ studies and has been proposed as a possible mechanism of recurrent IMR [7, 8]. Zhu et al. investigated pre- and post-repair mitral leaflet configurations in a 2DE study [7]. This study included 31 patients who underwent undersized annuloplasty for IMR and post-repair echocardiography 2 week to 2 months after surgery. Results showed that post-operative tethering was predominant for the posterior leaflet and that patients with recurrence had a significantly higher posterior leaflet angle than patients without recurrence [7]. The predominant role of posterior tethering in IMR recurrence is best explained by the fact that the anterior annulus is relatively fixed and therefore less influenced.
Although our study shows increased post-repair leaflet tethering, the extent of overall anterior and posterior leaflet tethering immediately after repair was similar among patient with recurrent and non-recurrent IMR in this study, which is insufficient evidence to explain it as a causative mechanism of IMR recurrence. In time, however, this may be a moving target with continued LV remodelling and dilatation which continue to exacerbate leaflet tethering and which may render patients prone to IMR recurrence. Hung et al. indeed showed that recurrence was associated with a higher LV diameter and LV sphericity index [2]. The fact that this is a moving target might be a good explanation for our results. 


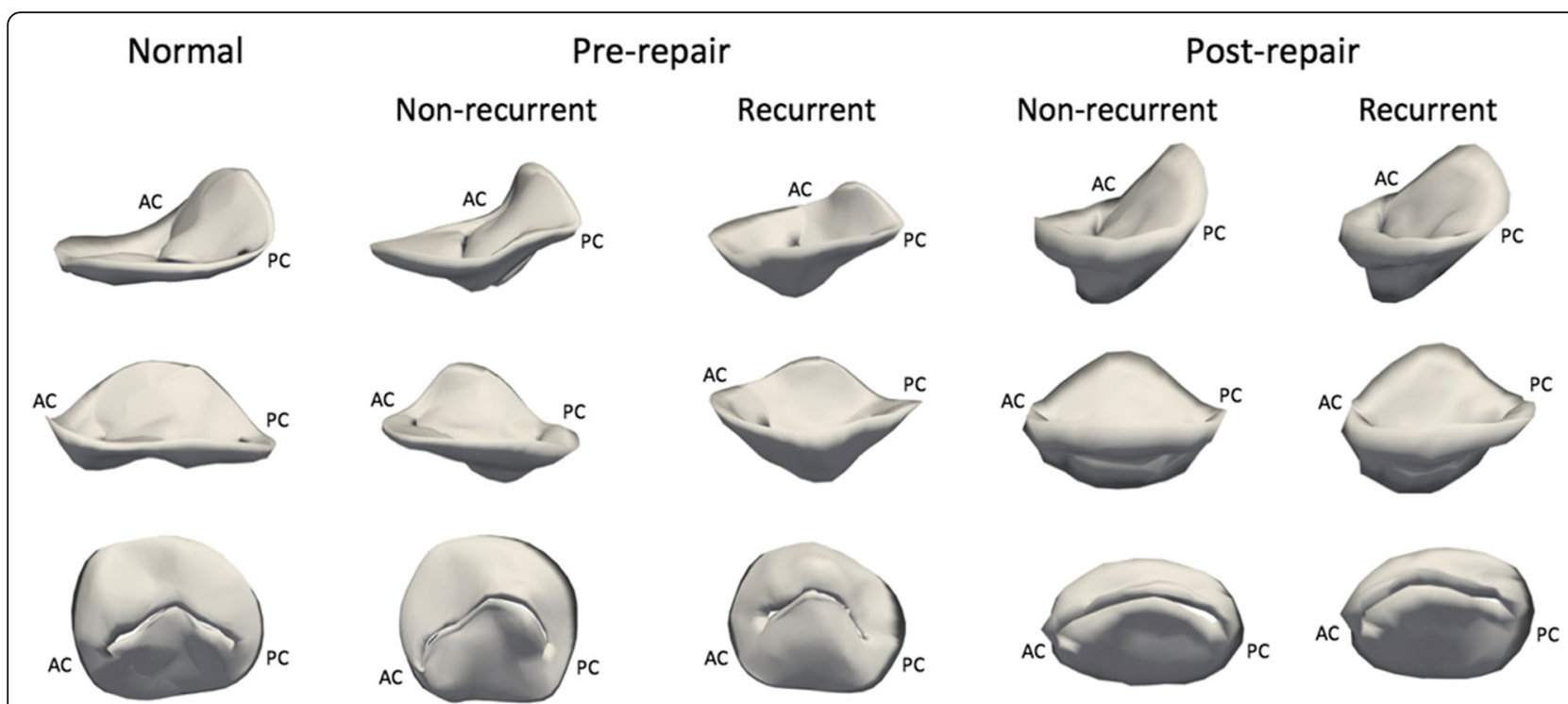

Fig. 2 Three-dimensional reconstructed models of a representative normal mitral valve and representative pre- and post-repair mitral valves that will and will not develop recurrent IMR after undersized ring annuloplasty: (top row) oblique commissure-to- commissure view, (middle row) oblique septolateral view, (bottom row) left ventricular view. $\mathrm{AC}=$ anterior commissure; $\mathrm{PC}=$ posterior commissure

Pre-repair leaflet tethering is basically a reflection of subvalvular remodeling in IMR and is a predictor of IMR recurrence in several studies [5, 14, 15]. Immediately after annuloplasty, the annular and leaflet tethering geometry changes, but subvalvular geometry does not. This process starts after repair and revascularization, and so it is not evident in the immediate post-repair phase. This may explain why immediate post-repair tethering measurements are not predictive for recurrent IMR. Additional quantitative 3DE analysis and modeling of the subvalvular apparatus (tendinal chords, papillary muscles and LV) should be performed in future studies both immediately after repair and several months after repair to further elucidate this concept.

The one and two year outcomes of the CTSN trial showed that there was no difference in LV diameter after mitral valve repair versus replacement, nor in a composite endpoint of major adverse cardiac or cerebrovascular related events, functional status or quality of life $[4,16]$. IMR recurrence rates were higher for the repair group. Though it should be noted that in the repair-group, LV end-systolic volume index for the non-recurrent IMR group was significantly lower compared to the recurrent IMR group. These findings also indicate that advanced LV remodeling and dilatation play a role in IMR recurrence.

A substudy of the CTSN trial by Capoulade et al focused on a relatively new parameter, the LV end-systolic diameter to ring size ratio, which appeared to be a significant predictor for IMR recurrence [17]. This "LVring mismatch" may be a valuable addition to the various predictors for IMR recurrence. Future treatment modalities should also focus on subvalvular targets in order to minimize "LV-ring mismatch" and the risk of IMR recurrence. We think that $3 \mathrm{DE}$ modeling may be a very useful and powerful addition to this combined valvularsubvalvular concept, which could guide future patientspecific surgical planning and decision making.

Our previous studies have shown that pre-repair 3DE mitral valve modeling is highly predictive of IMR recurrence and that its predictive value is much higher than that of $2 \mathrm{DE}$ mitral parameters $[5,6]$. The current $3 \mathrm{DE}$ mitral valve modeling study has two important additional clinical messages: (1) undersized annuloplasty severely exacerbates $3 \mathrm{DE}$ posterior leaflet tethering, and (2) immediate post-repair 3DE geometry and leaflet tethering do not predict IMR recurrence and are at this point of no additional value in guiding patient-specific intraoperative decision making.

There were several limitations in this study. (1) The number of patients was relatively small $(n=35)$ and follow-up was relatively short ( 6 months). Fifteen of the original 50 patients had intraoperative post-repair 3DE images of insufficient quality for modeling and were excluded. (2) The segmentation and modeling methodology of 3D TEE images requires time-consuming off-line analysis. Therefore, work is in progress to develop and validate an automated segmentation technique that will allow image processing and mitral leaflet segmentation in minutes rather than hours $[18,19]$. This tool can potentially be used in the operating room to guide surgical decision making for IMR. (3) The end point was an echocardiographic measurement of IMR recurrence, not a clinical outcome such as survival. However, there is strong evidence correlating IMR with reduced survival $[20,21]$. (4) Recurrent IMR is measured semi- 
quantitatively with transthoracic echocardiography color Doppler, where the jet area is expressed as a percentage of the LA area. Alternative assessments of IMR (regurgitant volume and effective regurgitant orifice area) were unfortunately not available in this study.

\section{Conclusions}

Undersized ring annuloplasty changes mitral geometry acutely, exacerbates leaflet tethering, and generally fixes IMR acutely, but it does not always fix the delicate underlying chronic problem of continued LV dilatation and remodeling. This may explain why pre-repair 3D valve geometry (which reflects chronic LV remodeling) is highly predictive of recurrent IMR, whereas immediate post-repair 3D valve geometry (which does not completely reflect chronic LV remodeling anymore) is not.

\section{Abbreviations}

2D(E): Two-Dimensional (Echocardiography); 3D(E): Three-Dimensional (Echocardiography); AC: Anterior Commissure; ATA: Anterior Tethering Angle; CABG: Coronary Artery Bypass Grafting; CTSN: Cardiothoracic Surgical Network; IMR: Ischemic Mitral Regurgitation; LV: Left Ventricle; MV: Mitral Valve; MVTa: Mitral Valve Tethering Area; NYHA: New York Heart Association; PC: Posterior Commissure; PCl: Percutaneous Coronary Intervention; PTA: Posterior Tethering Angle; TEE: Transesophageal Echocardiography

\section{Acknowledgements}

Not applicable.

\section{Authors' contributions}

All authors meet ICMJE guidelines for contribution. FM, IW, WB, and EL collected the data and wrote the manuscript. FM, IW, WB, AP, AA, EL, TE Contributed in data analysis. WB, MA, PY, JH, MM, KK, TG, FM, JG, RG participated in the design of the study and they revised and critically reviewed the manuscript. All authors have read, critically reviewed, and approved the final manuscript.

\section{Funding}

Funding was provided by grants from the National Heart, Lung and Blood Institute of the National Institutes of Health, Bethesda, MD (HL 103723, HL073021, and HL147256).

\section{Availability of data and materials}

Please contact the corresponding author for data requests.

\section{Ethics approval and consent to participate}

This study was approved by the Institutional Review Boards of the University of Pennsylvania, the University of Pittsburgh, and the Beth Israel Deaconess Medical Center. Written informed consent was obtained from all patients.

\section{Consent for publication}

Not applicable.

\section{Competing interests}

The authors declare that they have no competing interests.

\section{Author details}

${ }^{1}$ Gorman Cardiovascular Research Group, University of Pennsylvania, Philadelphia, PA, USA. ²Department of Cardiothoracic Surgery, University of Groningen, University Medical Center Groningen, Groningen, the Netherlands. ${ }^{3}$ Department of Surgery, University of Pennsylvania, Philadelphia, PA, USA. ${ }^{4}$ Department of Radiology, University of Pennsylvania, Philadelphia, PA, USA. ${ }^{5}$ Department of Cardiology, Massachusetts General Hospital, Harvard Medical School, Boston, MA, USA. ${ }^{6}$ Department of Cardiothoracic Surgery, Beth Israel Deaconess Medical Center, Harvard Medical School, Boston, MA, USA. 'Department of Cardiothoracic Surgery,
University of Pittsburgh, Pittsburgh, PA, USA. ${ }^{8}$ Department of Anesthesia, Beth Israel Deaconess Medical Center, Harvard Medical School, Boston, MA USA.

Received: 20 January 2020 Accepted: 4 May 2020

Published online: 02 July 2020

\section{References}

1. McGee EC, Gillinov AM, Blackstone EH, Rajeswaran J, Cohen G, Najam F, et al. Recurrent mitral regurgitation after annuloplasty for functional ischemic mitral regurgitation. J Thorac Cardiovasc Surg. 2004;128:916-24.

2. Hung J, Papakostas L, Tahta SA, Hardy BG, Bollen BA, Duran CM, et al. Mechanism of recurrent ischemic mitral regurgitation after annuloplasty: continued LV remodeling as a moving target. Circulation. 2004;110:II85-90.

3. Dahlberg PS, Orszulak TA, Mullany CJ, Daly RC, Enriquez-Sarano M, Schaff HV. Late outcome of mitral valve surgery for patients with coronary artery disease. Ann Thorac Surg. 2003;76:1539-487.

4. Goldstein D, Moskowitz AJ, Gelijns AC, Ailawadi G, Parides MK, Perrault LP, et al. Two-year outcomes of surgical treatment of severe ischemic mitral regurgitation. N Engl J Med. 2015;374:344-53.

5. Bouma W, Lai EK, Levack MM, Shang EK, Pouch AM, Eperjesi TJ, et al. Preoperative three-dimensional valve analysis predicts recurrent ischemic mitral regurgitation after mitral annuloplasty. Ann Thorac Surg. 2016;101: 567-75.

6. Wijdh-den Hamer IJ, Bouma W, Lai EK, Levack MM, Shang EK, Pouch AM, et al. The value of preoperative 3-dimensional over 2-dimensional valve analysis in predicting recurrent ischemic mitral regurgitation after mitral annuloplasty. J Thorac Cardiovasc Surg. 2016;152:847-59.

7. Zhu F, Otsuji Y, Yotsumoto G, Yuasa T, Ueno T, Yu B, et al. Mechanism of persistent ischemic mitral regurgitation after annuloplasty: importance of augmented posterior mitral leaflet tethering. Circulation. 2005;112:1396-401.

8. Kuwahara E, Otsuji Y, Iguro Y, Ueno T, Zhu F, Mizukami N, et al. Mechanism of recurrent/persistent ischemic/functional mitral regurgitation in the chronic phase after surgical annuloplasty: importance of augmented posterior leaflet tethering. Circulation. 2006;114:1529-34.

9. McCully RB, Enriquez-Sarano M, Tajik AJ, Seward JB. Overestimation of severity of ischemic/functional mitral regurgitation by color Doppler jet area. Am J Cardiol. 1994;74:790-3.

10. Jasser AS, Brinster CJ, Vergnat M, Robb JD, Eperjesi TJ, Puch AM, et al. Quantitative mitral valve modeling using real-time three-dimensional echocardiography: technique and repeatability. Ann Thorac Surg. 2011;91: 165-71.

11. Ryan LP, Jackson BM, Parish LM, Sakamoto H, Plappert TJ, St John-Sutton M, et al. Mitral valve tenting index for assessment of subvalvular remodeling. Ann Thorac Surg. 2007;84:1243-9.

12. Gillinov AM, Wierup PN, Blackstone EH, Bishay ES, Cosgrove DM, White J, et al. Is repair preferable to replacement for ischemic mitral regurgitation? J Thorac Cardiovasc Surg. 2001:122:1125-41.

13. Grossi EA, Bizekis CS, LaPietra A, Derivaux CC, Galloway AC, Ribakove GH, et al. Late results of isolated mitral annuloplasty for "functional" ischemic mitral insufficiency. J Card Surg. 2001;16:328-33.

14. Magne J, Pibarot P, Dagenais F, Hachicha Z, Dumesnil JG, Sénéchal M. Preoperative posterior leaflet angle accurately predicts outcome after restrictive mitral valve annuloplasty for ischemic mitral regurgitation. Circulation. 2007:115:782-91.

15. Van Garsse L, Gelsomino S, Parise O, Lucã F, Cheriex E, Lorusso R, et al. Systolic papillary muscle dyssynchrony predicts recurrence of mitral regurgitation in patients with ischemic cardiomyopathy (ICM) undergoing mitral valve repair. Echocardiography. 2012;29:1191-200.

16. Acker MA, Parides MK, Perrault LP, Moskowitz AJ, Gelijns AC, Voisine P, et al. Mitral-valve repair versus replacement for severe ischemic mitral regurgitation. N Engl J Med. 2014;370:23-32.

17. Capoulade R, Zeng X, Overbey JR, Ailawadi G, Alexander JH, Ascheim D, et al. Impact of left ventricular to mitral valve ring mismatch on recurrent ischemic mitral regurgitation after ring annuloplasty. Circulation. 2016;134: 1247-56.

18. Pouch AM, Jackson BM, Lai E, Takebe M, Tian S, Cheung AT, et al. Modeling the myxomatous mitral valve with three-dimensional echocardiography. Ann Thorac Surg. 2016;102:703-10.

19. Pouch AM, Wang H, Takabe M, Jackson BM, Gorman JH, Gorman RC, et al. Fully automatic segmentation of the mitral leaflets in 3D transesophageal 
echocardiographic images using multi-atlas joint label fusion and deformable medial modeling. Med Image Anal. 2014;18:118-29.

20. Trichon BH, Felker GM, Shaw LK, Cabell CH, O'Connor CM. Relation of frequency and severity of mitral regurgitation to survival among patients with left ventricular systolic dysfunction and heart failure. Am J Cardiol. 2003;91:538-43.

21. Grigioni F, Enriquez-Sarano M, Zehr KJ, Bailey KR, Tajik AJ. Ischemic mitral regurgitation: long-term outcome and prognostic implications with quantitative Doppler assessment. Circulation. 2001;103:1759-64.

\section{Publisher's Note}

Springer Nature remains neutral with regard to jurisdictional claims in published maps and institutional affiliations.

Ready to submit your research? Choose BMC and benefit from:

- fast, convenient online submission

- thorough peer review by experienced researchers in your field

- rapid publication on acceptance

- support for research data, including large and complex data types

- gold Open Access which fosters wider collaboration and increased citations

- maximum visibility for your research: over $100 \mathrm{M}$ website views per year

At $B M C$, research is always in progress.

Learn more biomedcentral.com/submissions 